Article

\title{
Determination of Optimum Concentration of Benzimidazole Improving the Cathodic Disbonding Resistance of Epoxy Coating
}

\author{
Saghar Nabavian ${ }^{1}$, Reza Naderi ${ }^{2, *}$ and Najmeh Asadi ${ }^{2}$ \\ 1 Department of Marine Science and Technology, College of Marine Chemistry, Islamic Azad University, \\ P.O. Box 14515-755 Tehran, Iran; sagharnabavian@gmail.com \\ 2 School of Metallurgy and Materials Engineering, College of Engineering, University of Tehran, \\ P.O. Box 11155-4563 Tehran, Iran; najmehasadi@ut.ac.ir \\ * Correspondence: rezanaderi@ut.ac.ir; Tel.: +98-21-82084075; Fax: +98-21-88006076
}

Received: 7 November 2018; Accepted: 13 December 2018; Published: 19 December 2018

\begin{abstract}
This study is aimed to evaluate the effect of concentrated benzimidazole (BIM) on the cathodic disbonding $(\mathrm{CP})$ of an epoxy coating applied on steel substrate. For this purpose, the polymeric coatings, formulated with different concentrations of BIM $(0 \mathrm{wt} . \%, 0.5 \mathrm{wt} . \%, 0.75 \mathrm{wt} . \%$, and $1 \mathrm{wt} . \%$, were subjected to the $\mathrm{CP}$ test at the potential of $-1.2 \mathrm{~V}$ vs. $\mathrm{Ag} / \mathrm{AgCl}$ during $24 \mathrm{~h}$ immersion in $3.5 \mathrm{wt} . \% \mathrm{NaCl}$ solutions. The optimum formulation was found through taking advantage of the CP test results, FESEM/EDX, and EIS data. Moreover, a pull-off test was used to measure the wet adhesion strength. For insight into the inhibition function of the organic inhibitor, the behavior of steel in the sodium chloride solutions, with and without BIM, was compared using EIS and surface analysis.
\end{abstract}

Keywords: epoxy coating; EIS; organic inhibitor; benzimidazole; cathodic disbanding

\section{Introduction}

For protection of metals exposed to a corrosive environment, application of organic coatings is a reliable way. In the case of coated metals, bare metal is exposed to the aggressive environment in the damaged or defect areas of coating, leading to the occurrence and progress of underfilm corrosion. Therefore, cathodic protection is proposed to resolve the problem. In fact, organic coatings applied on the metallic substrates reduce the current required for cathodic protection. Despite the many advantages of cathodic protection, the technique may increase the possibility of coating delamination. Some parameters such as coating thickness, coating composition, surface treatment, dissolved oxygen, $\mathrm{NaCl}$ concentration, and cathodic potential can affect the delaminated area [1-6]. The voltage applied for cathodic protection promotes the reduction of oxygen penetrating through the coating matrix. Therefore, $\mathrm{OH}^{-}$ions accumulate in the metal/coating interface. As sodium cations access the disbonding front, the alkalinity can destroy the bond between the coating and metal surface, particularly on the edge of defects [7-14].

One of the effective strategies for controlling the film delamination is to modify the coating formulation. For instance, addition of anticorrosion pigments [15-17], organic inhibitors, e.g., azole derivatives [18-20], thioglycolate esters, mercaptocarboxylic acids [21], organic sulfides, organic amines, organic phosphates, phenols [22] disodium oleamidesulfosucinate, lignosulfonic acid-doped polyanilin [23], and also inhibitor loaded nanocontainers [24] have been proposed to increase the coating resistance against the destroying phenomena. The electrolyte penetrating into the coating may transfer organic inhibitor molecules and inhibiting species liberated from pigment particles to 
the interface, where the materials make a complex passive layer on the metal surface, blocking the active regions and reducing the rate of electrochemical reactions [25-29]. In the case of inhibitor loaded nanocontainers, Izadi et al. [24], for example, showed that release of Nettle molecules as green corrosion inhibitor and zinc cations from a nanocontainer, synthesized by l-b-l process with the core of $\mathrm{Fe}_{3} \mathrm{O}_{4}$ nanoparticles, provide epoxy coating with a significant cathodic disbonding protection. Moreover, the positive effect of zinc aluminum hydrotalcite intercalated with benzothiazolylthio-succinic acid on the cathodic delamination resistance of epoxy coating was reported by Hang et al. [30]. Interestingly, the influence of either direct or indirect addition of corrosion inhibitors to the conversion coatings or any pretreatments on the cathodic delamination of overlaying polymeric films has been studied in some literature [24,31,32]. Ramezanzadeh et al. [31] achieved an improved cathodic disbonding and adhesion properties through application of epoxy coating on the steel substrate covered by zinc phosphate conversion coating containing poly(vinyl) alcohol. Pretreatment of steel with silane layer incorporating amino and isocyanate silane functionalized graphene oxide nanosheets was shown to decrease the cathodic disbondment of epoxy top coating [32].

Previously, we reported the positive role of second and third generations of phosphate based anticorrosion pigments on the function of epoxy coating on the steel substrate in the condition of its application of cathodic protection [15-17]. In other words, zinc aluminum phosphate, zinc aluminum polyphosphate, and strontium aluminum polyphosphate (zinc-free pigment) were shown to play an important role in the disbonding front through decreasing $\mathrm{pH}$ and the deposition of an insoluble layer on the surface, which disrupts electrochemical reactions and increases the coating-metal bonding strength. In this work, we include benzimidazole as an organic corrosion inhibitor to an epoxy coating formulation to reduce the cathodic disbandment rate. In order to find the most effective inhibitor concentration, electrochemical impedance spectroscopy (EIS), pull-off test, and surface analysis methods were employed.

\section{Experimental}

\subsection{Materials and Sample Preparation}

ST37 steel panels with the composition mentioned in the previous work [15] and with a $1 \mathrm{~mm}$ thickness were polished using magnetic polisher to reach a desirable surface, then degreasing with acetone. In the solution phase study, the panels were immersed in $3.5 \mathrm{wt} . \% \mathrm{NaCl}$ aqueous solutions containing $1 \mathrm{mM}$ of Benzimidazole (BIM), purchased from Merck and used with no further purification. To prepare polymeric coatings, $0 \mathrm{wt} . \%, 0.5 \mathrm{wt} . \%, 0.75 \mathrm{wt} . \%$, and $1 \mathrm{wt} . \%$ of the organic inhibitor were mixed in polyamide (Crayamid 115). Then, the prepared polyamide was mixed in epoxy resin Epiran-01X75 (Khouzestan petrochemical Co., Bandar Jomeiny, Iran) at a stoichiometric ratio of 60:100. BYK-306 (BYK-Chemie GmbH, Wesel, Germany) was used as a leveling agent in the coating formulation. After curing at a temperature of $80^{\circ} \mathrm{C}$ for $40 \mathrm{~min}$, the thickness of dry film measured using Elcometere-445 (Elcometer Inc., Manchester, UK) was approximately $20 \pm 3 \mu \mathrm{m}$.

\subsection{Methods}

The electrochemical impedance spectroscopy was carried out using Autolab PGSTAT12 (Metrohm AG, Herisau, Switzerland) an open circuit potential (OCP) in the frequency domain of $10 \mathrm{kHz}$ to $10 \mathrm{mHz}$ using a $10 \mathrm{mV}$ amplitude perturbation. A setup containing the sample (bare metal or coated substrate) as working electrode, platinum counter electrode, and $\mathrm{Ag} / \mathrm{AgCl}$ reference electrode was used for EIS test. The electrical connection was provided by a copper wire attached to one surface of the working electrode. For the bare plates with $1 \mathrm{~cm}^{2}$ surface area exposed to $3.5 \mathrm{wt} . \% \mathrm{NaCl}$ solutions with and without $1 \mathrm{mM}$ benzimidazole, EIS tests were performed at room temperature after 5 and $24 \mathrm{~h}$ of immersion. The electrochemical tests for the coated samples after subjection to a cathodic disbonding test were conducted after 12 and $24 \mathrm{~h}$ immersion in $3.5 \mathrm{wt} . \% \mathrm{NaCl}$ solution. The data of EIS performed on three replicates was analyzed with the use of ZsimpWin software (v3.22). 
The steel samples, which were covered by the epoxy coatings containing different amounts of BIM with an artificial circular hole (1 $\mathrm{mm}$ in diameter), were subjected to cathodic disbonding tests. In the test, the samples immersed in $3.5 \mathrm{wt} . \% \mathrm{NaCl}$ solution were polarized at $-1.2 \mathrm{~V} \mathrm{vs.} \mathrm{Ag} / \mathrm{AgCl}$. Some radial cuts intersecting at the hole were provided on the films at the end of cathodic disbonding test and the detached coatings were removed with a sharp knife to determine the average surface area of disbondment. In other words, the average distance between the hole and intact parts of polymeric film was considered as the radius of disbondment.

After attachment of dollies on the epoxy coating using a 2-part Araldit epoxy, a pull-off test was performed with a PosiTest digital adhesion tester (DeFelsko Corp., Ogdensburg, NY, USA). In the wet mode, the dollies were detached from the sample surface after $24 \mathrm{~h}$ immersion in $3.5 \mathrm{wt} . \%$ $\mathrm{NaCl}$ solution to obtain bonding strength of the coatings with and without the organic inhibitor.

A field emission electron microscopy (FE-SEM/EDS, TESCAN MIRA 3 Lumbers, Brno, Czech Republic) was employed to characterize the surface of (1) bare steel after $24 \mathrm{~h}$ dipping in 3.5 wt. $\% \mathrm{NaCl}$ solution with $1 \mathrm{mM}$ BIM and (2) areas beneath the delaminated epoxy coating with BIM after a cathodic disbonding test.

\section{Results and Discussion}

Prior to introducing of the inhibitor into the epoxy coating, the effect of BIM on the corrosion of uncoated ST37 panels in the sodium chloride electrolyte was evaluated by the electrochemical impedance spectroscopy technique. Figure 1 compares the Nyquist plots of bare specimens after five and $24 \mathrm{~h}$ immersion in $3.5 \mathrm{wt} . \% \mathrm{NaCl}$ electrolyte with and without $1 \mathrm{mM} \mathrm{BIM}$. In the presence of the organic molecule in the two immersion periods, semicircles with larger diameter were visible, indicating a kind of corrosion inhibition. Moreover, increasing the time of exposure to the blank electrolyte resulted in smaller spectra, while the exposure period had no noticeable effect on the spectra in the presence of BIM. Since only one relaxation time was detected in the AC impedance spectra of both cases after five and $24 \mathrm{~h}$ exposure, the simple equivalent circuit illustrated in Figure 2 was selected to model the data. As shown in Figure $2, R_{\mathrm{S}}$ represents the solution resistance, $R_{\mathrm{ct}}$ the charge transfer resistance, and $\mathrm{CPE}_{\mathrm{dl}}$ the constant phase element of double layer. The data resulting from the modeling is presented in Table 1.

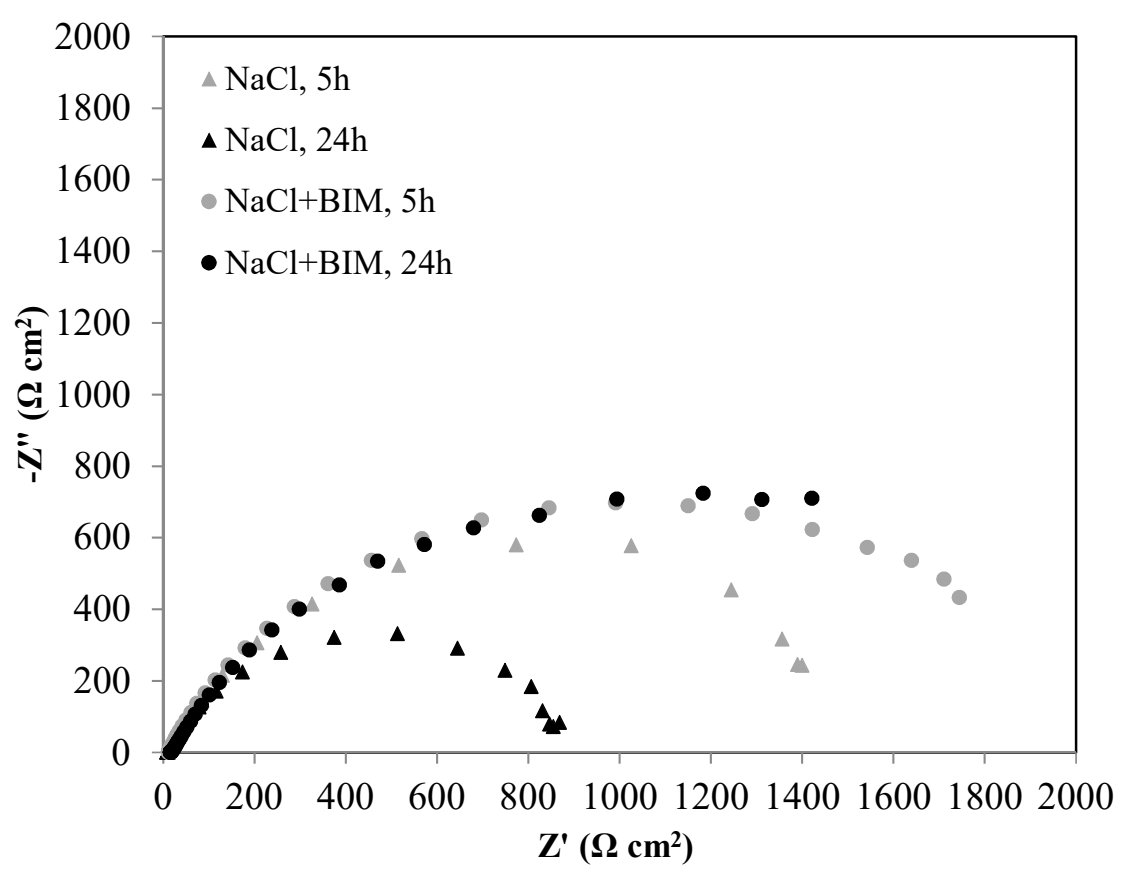

Figure 1. Nyquist diagrams of the bare specimens dipped in $3.5 \mathrm{wt} . \% \mathrm{NaCl}$ electrolyte with and without $1 \mathrm{mM}$ BIM after 5 and $24 \mathrm{~h}$. 
In order to determine the double layer capacitance values in Table 1, Equation (1) was used [33]:

$$
C_{\mathrm{dl}}=\left(Y_{0} R_{\mathrm{ct}}{ }^{-n}\right)^{1 / n}
$$

where $Y_{0}$ and $n$ are, respectively, the admittance and exponent of CPE.

Some important features can be derived from the table. The presence of BIM in the aggressive electrolyte resulted in a decrease in double layer capacitance and increase in the charge transfer resistance. For instance, the $R_{\mathrm{ct}}$ value in the presence of BIM was approximately 2.5 times higher than that in the absence of BIM at the end of the $24 \mathrm{~h}$ dipping period. Besides the magnitude, increasing the time of exposure to the blank sodium chloride solution had a decreasing effect on the charge transfer resistance, while an increasing trend was observed for the metallic specimen dipped in the electrolyte with BIM. Considering the inverse proportion of the charge transfer resistance to corrosion current density, the trend and magnitude of the resistance parameter in the presence of the organic molecule indicated an inhibition function [34]. The replacement of a water molecule with the organic molecules (BIM) might be responsible for the drop in the double layer capacitance values after both five and 24 dipping durations. These results were in agreement with the data we acquired for some organic inhibitors in the chloride solution $[35,36]$. The organic molecules existing in the extract of Mentha longifolia in sodium chloride solution was reported to provide a maximum inhibition efficiency of $69.5 \%$ after $24 \mathrm{~h}$ [35]. We also found, in another research, that the presence of 4,5-imidazoledicarboxylic in $\mathrm{NaCl}$ solution led to a kind of corrosion inhibition for steel plates and the obtained impedance spectra during $24 \mathrm{~h}$ immersion had only a one time constant [36].

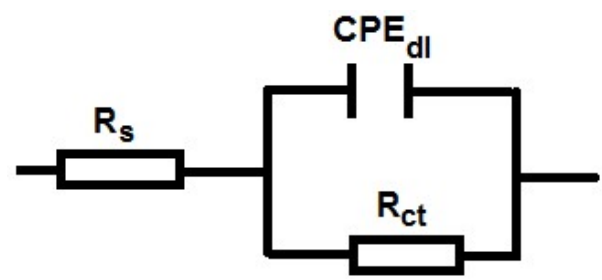

Figure 2. The equivalent circuit for modeling of the results of EIS test on the bare ST37 steels after 5 and $24 \mathrm{~h}$ dipping in $3.5 \mathrm{wt} . \% \mathrm{NaCl}$ solution in the absence and presence of $1 \mathrm{mM}$ BIM.

Table 1. The data resulting from modeling of the AC impedance spectra of bare ST37 steels after 5 and $24 \mathrm{~h}$ dipping in $3.5 \mathrm{wt} . \% \mathrm{NaCl}$ solution in the absence and presence of $1 \mathrm{mM}$ BIM.

\begin{tabular}{cccc}
\hline BIM Concentration $(\mathbf{m M})$ & Immersion Time (h) & $\boldsymbol{R}_{\mathrm{ct}}\left(\boldsymbol{\Omega} \cdot \mathbf{c m}^{\mathbf{2}}\right)$ & $\boldsymbol{C}_{\mathrm{d} \mathbf{l}}\left(\boldsymbol{\mu} \mathbf{F} \cdot \mathbf{c m}^{-2}\right)$ \\
\hline \multirow{2}{*}{0} & 5 & 1292 & 752 \\
& 24 & 912 & 529 \\
\hline \multirow{2}{*}{1} & 5 & 2001 & 469 \\
& 24 & 2256 & 404 \\
\hline \multirow{2}{*}{ Standard deviation } & $R_{\mathrm{c}}$ & \multicolumn{2}{c}{$1.7 \%-9.3 \%$} \\
& $C_{\mathrm{dl}}$ & \multicolumn{2}{c}{$3.8 \%-13.8 \%$} \\
\hline
\end{tabular}

The appearance of bare ST37 specimens after $24 \mathrm{~h}$ immersion in the $\mathrm{NaCl}$ solution with and without the organic moiety is shown in Figure 3. A decrease of corrosion products on the specimen surface immersed in the electrolyte containing benzimidazole was clearly visible, confirming the electrochemical data.

In order to further investigate the function of BIM, SEM-EDS tests were performed on the surface of bare ST37 specimens after $24 \mathrm{~h}$ immersion in the electrolyte (Figure 4). As seen from Figure 4, a layer was observed on the surface exposed to the $\mathrm{NaCl}$ solution containing BIM. The elemental composition of the detected layer, which was obtained by EDS, was Fe (49.64\%), Na (1.41\%), Cl (0.58\%), $\mathrm{O}(36.84 \%), \mathrm{N}(3.35 \%)$, and $\mathrm{C}(8.18 \%)$. The presence of nitrogen and carbon in the EDS surface analysis result may show that the organic BIM molecule engaged in the surface film formation. 


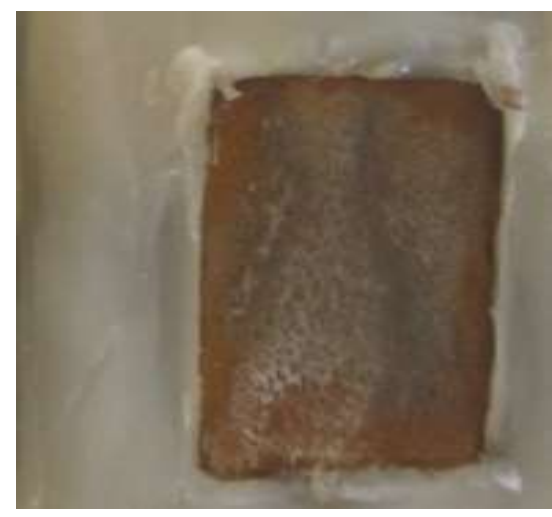

(a)

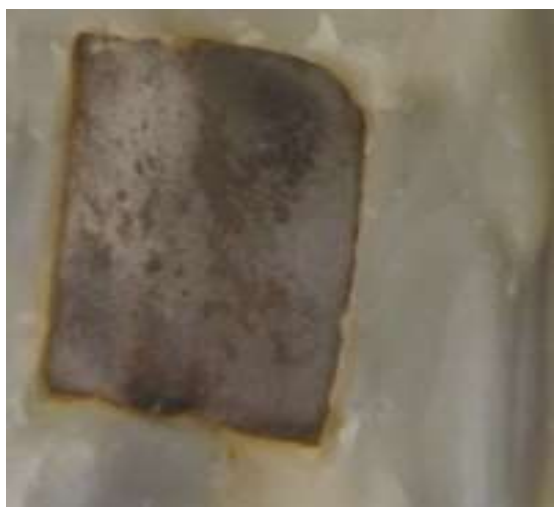

(b)

Figure 3. The appearance of bare ST37 specimens after $24 \mathrm{~h}$ immersion in the $\mathrm{NaCl}$ solution with no additives (a) and with BIM (b).

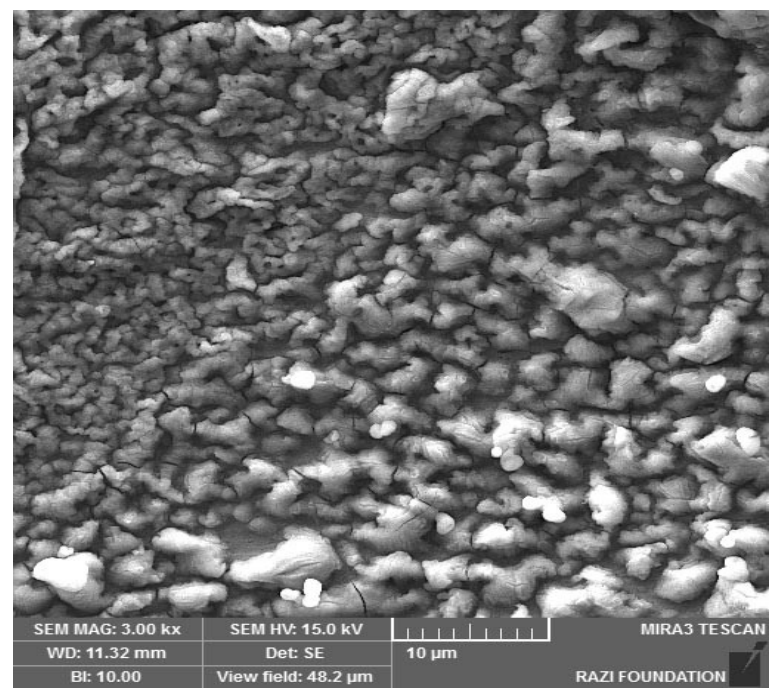

Figure 4. The result of FE-SEM test on bare sample surface after $24 \mathrm{~h}$ exposure to $3.5 \mathrm{wt} . \% \mathrm{NaCl}$ electrolyte containing $1 \mathrm{mM}$ BIM.

At the next step, different concentrations of benzimidazole $(0 \mathrm{wt} . \%, 0.5 \mathrm{wt} . \%, 0.75 \mathrm{wt} . \%$, and $1 \mathrm{wt} . \%$ ) were introduced into the epoxy-polyamide coating formulation applied on ST37 substrate and cathodic disbonding test $(-1.2 \mathrm{~V}$ vs. $\mathrm{Ag} / \mathrm{AgCl}$ for $24 \mathrm{~h}$ ) was conducted on the coated samples. The evolution of disbonded area for different samples is demonstrated in Figure 5 as bar diagrams. From the figure, the disbonded areas for the samples either with or without the organic inhibitor increased with elapsing the immersion time. Moreover, the presence of BIM had a positive impact on the cathodic disbonding resistance. To top it off, it was clearly visible that the polymeric coating resistance to cathodic disbonding is noticeably dependent on the concentration of bezimidazole. The coating containing $0.75 \mathrm{wt} . \%$ BIM revealed the lowest disbondment and generally the disbonded areas increased following the order $0 \mathrm{wt} . \%>1 \mathrm{wt} . \%>0.5 \mathrm{wt} . \%>0.75 \mathrm{wt} . \%$ BIM. Inclusion of the organic inhibitor into the polymeric matrix may result in some contradictory impacts on the coating function. The disbonding front might be covered by a protective layer when the organic molecules access the substrate surface. This can improve the strength of bonding of the polymeric film to the metallic specimen and decrease the generation of hydroxyl ion as a result of restriction of electrochemical reactions on the surface. This was previously shown in the results of the solution phase study. By increasing the organic molecule content, the chance of formation of the mentioned surface film increases. On the other hand, the interaction between molecules of inhibitor and polymeric matrix may affect the curing process and final film integrity [37]. Another drawback of the addition of the organic 
material to the coating is uncontrollable liberation of inhibiting species [38]. The consequence of these contradictory issues was inferior and superior behavior of the epoxy coatings with one and $0.75 \mathrm{wt} . \%$ BIM, respectively. This was in agreement with the results of our previous works, where exceeding the optimum concentration of corrosion inhibitors adversely affected the coating performance [35,39]. In the case of organic inhibitors liberated from Mentha longifolia, the efficient concentration was $200 \mathrm{ppm}$ and incorporation of $400 \mathrm{ppm}$ caused coating to lose its integrity. In other words, the amount of this green inhibitor was suggested to have a negative effect on the film formation and to decrease the crosslinking density, making the film more permeable [35]. Interestingly, the disbonded surface area of epoxy-polyamide coating containing $0.75 \mathrm{wt} . \%$ BIM was approximately half of that of the rest after $24 \mathrm{~h}$ subjection to the cathodic disbonding test. The effective role of organic molecules on the cathodic disbonding resistance of polymeric coating was also shown in Izadi and coworkers research where epoxy coating was formulated by a nanocontainer doped with Nettle molecules as a green corrosion inhibitor [24].

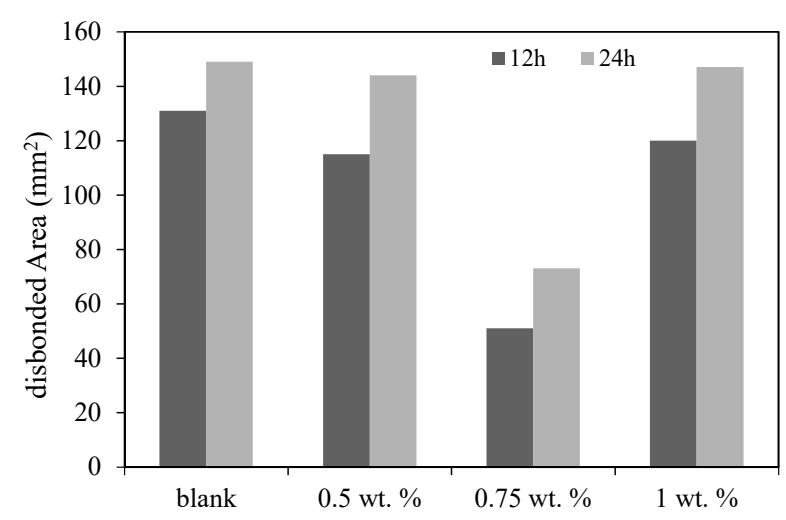

Figure 5. Evolution of delaminated area for the epoxy-polyamide coatings with different formulations on the ST37 substrate.

To provide further investigation on the effect of the concentration of BIM corrosion inhibitor on the cathodic disbonding of epoxy coating applied on ST37, AC impedance spectra were gathered. According to the literature, the cathodic delamination behavior of polymeric coatings can be analyzed through taking advantage of the EIS data [16,40,41]. For instance, Chen et al. [41] used electrochemical impedance spectroscopy for investigating the mechanism of the cathodic disbonding behavior of the three-layer polyethylene pipeline coating in chloride solution. The Nyquist plots for the ST37 panels coated with the epoxy films including different concentrations of BIM after polarization at $-1.2 \mathrm{~V}$ vs. $\mathrm{Ag} / \mathrm{AgCl}$ in $3.5 \mathrm{wt} . \% \mathrm{NaCl}$ solution for 12 and $24 \mathrm{~h}$ are shown in Figure 6, and a typical Bode-phase and modulus diagram of the metal coated with epoxy containing $0.75 \mathrm{wt} . \%$ BIM is illustrated in Figure 7 . Emerging as only a one time constant for all spectra caused a simple selection $R(R C)$ equivalent circuit for modeling of the data. The results of fitting with an $R(R C)$ equivalent circuit are introduced in Table 2 . From the Nyquist diagrams for both exposure periods, the sample containing $0.75 \mathrm{wt} . \%$ BIM was characterized with the largest semicircles. While semicircles all got smaller by expanding the exposure, the sample containing $0.75 \mathrm{wt} . \%$ of corrosion inhibitor kept its superiority. In addition to showing the dependency of the resistance and capacitance elements on the corrosion inhibitor amount, the data presented in Table 2 revealed that the samples with $0.75 \mathrm{wt} . \%$ BIM possess the highest resistance and the lowest capacitance values, particularly after $24 \mathrm{~h}$. In agreement with the results of a cathodic disbonding test in Figure 5, the superiority of this sample was found on the basis of the direct and inverse proportion of capacitance and resistance, respectively, to the delaminated surface area [42,43]. The substrate surface coverage with a layer composed of the organic molecules might be responsible for the behavior, as discussed before. Accordingly, the progress of delamination for all specimens, by increasing the time of subjection to the cathodic disbonding test, can also be evidenced. 

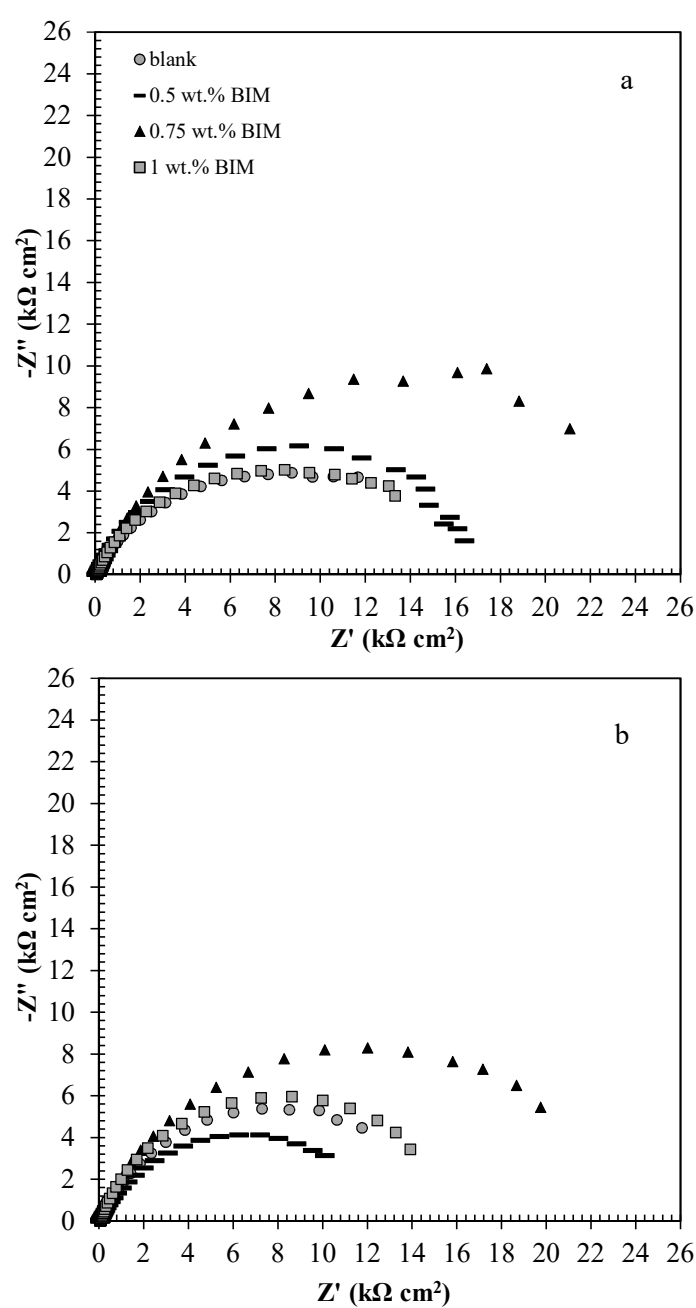

Figure 6. Nyquist plots of the ST37 panels coated with the epoxy films including different concentrations of BIM (0 wt. \%, $0.5 \mathrm{wt} . \%, 0.75 \mathrm{wt} . \%$, and $1 \mathrm{wt} . \%)$ after polarization at $-1.2 \mathrm{~V}$ vs. $\mathrm{Ag} / \mathrm{AgCl}$ in 3.5 wt.\% $\mathrm{NaCl}$ solution for (a) 12 and (b) $24 \mathrm{~h}$.

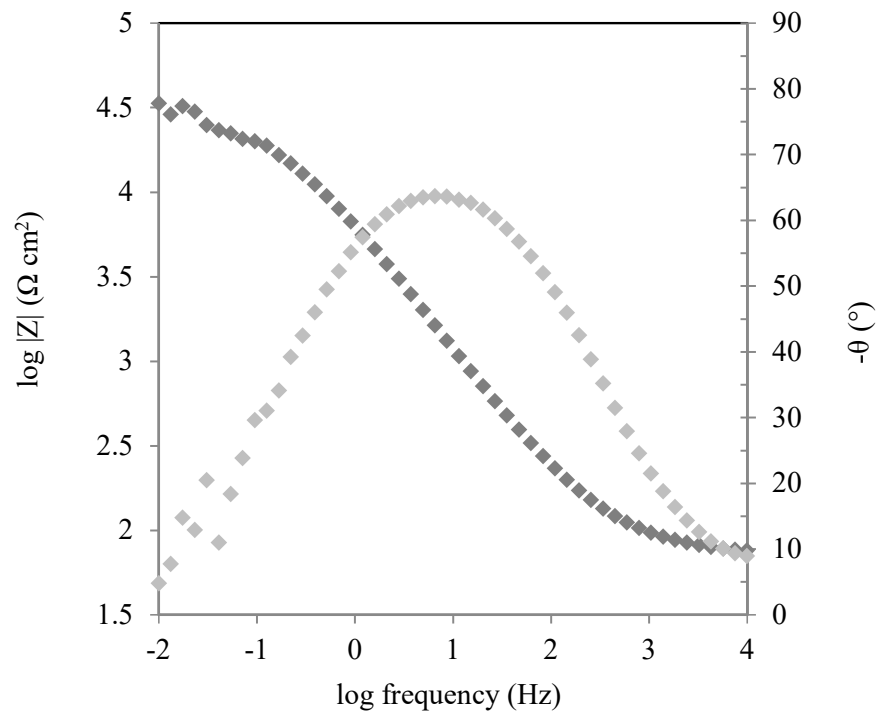

Figure 7. Typical Bode-modulus and phase diagram obtained for ST37 panel coated with the epoxy containing $0.75 \mathrm{wt} . \%$ of BIM after $12 \mathrm{~h}$ polarization at $-1.2 \mathrm{~V}$ vs. $\mathrm{Ag} / \mathrm{AgCl}$ in $3.5 \mathrm{wt} . \% \mathrm{NaCl}$ solution. 
Table 2. Fitting results of spectra of the ST37 panels coated with the epoxy films including different concentrations of BIM ( 0 wt. $\%, 0.5$ wt. $\%, 0.75$ wt. $\%$, and $1 \mathrm{wt} . \%)$ after polarization at $-1.2 \mathrm{~V}$ vs. $\mathrm{Ag} / \mathrm{AgCl}$ in $3.5 \mathrm{wt} . \% \mathrm{NaCl}$ solution for 12 and $24 \mathrm{~h}$.

\begin{tabular}{|c|c|c|c|}
\hline BIM Concentration (wt.\%) & Immersion Time (h) & $R\left(\mathrm{k} \Omega \cdot \mathrm{cm}^{2}\right)$ & $C\left(\mu \mathrm{F} \cdot \mathrm{cm}^{-2}\right)$ \\
\hline \multirow{2}{*}{0} & 12 & 15.7 & 39.6 \\
\hline & 24 & 14.8 & 39.4 \\
\hline \multirow{2}{*}{0.5} & 12 & 17.5 & 31.1 \\
\hline & 24 & 12.5 & 43.4 \\
\hline \multirow{2}{*}{0.75} & 12 & 27.8 & 36.2 \\
\hline & 24 & 23.6 & 22.9 \\
\hline \multirow[b]{2}{*}{1} & 12 & 15.9 & 17.2 \\
\hline & 24 & 14.9 & 46.4 \\
\hline \multirow{2}{*}{ Standard deviation } & $R$ & \multirow{2}{*}{\multicolumn{2}{|c|}{$\begin{array}{c}1.3 \%-10.1 \% \\
3 \%-14.4 \%\end{array}$}} \\
\hline & C & & \\
\hline
\end{tabular}

To assess the effect of BIM on the adhesion strength of epoxy coating with and without $0.75 \mathrm{wt} . \%$ BIM (the optimum concentration previously determined in EIS and cathodic disbonding tests), pull-off test was employed. Adhesion strength values of the coatings with and without BIM before and after $24 \mathrm{~h}$ immersion in $3.5 \mathrm{wt} . \% \mathrm{NaCl}$ are shown in Figure 8. As can be observed from the figure in the dry mode, the coating with no inhibitor revealed stronger adhesion to the ST37 substrate. This fact could be related to the increase of the coating heterogeneity as a result of the introduction of the inhibitor. The heterogeneity might lead to a decrease in the adhesion of coating film to the metal surface [10]. In contrast, the coating formulated with $0.75 \mathrm{wt} . \%$ BIM possessed a higher value of bonding strength after 24 of dipping in the aggressive electrolyte. As mentioned previously, in both the coating and solution phase studies, the surface layer precipitated in the presence of BIM, limiting the electrochemical reaction rate and reinforcing the interface, can increase the polymeric film adhesion. Moreover, it is also reported that the presence of the inhibitor may lead to the stabilization of the corrosion products, decreasing coating delamination [10].



Figure 8. The impact of BIM on the bonding strength of the epoxy-polyamide coating before (dry) and after $24 \mathrm{~h}$ immersion in $3.5 \mathrm{wt} . \% \mathrm{NaCl}$ electrolyte (wet).

The result of SEM analysis of the ST37 sample surface beneath the disbonded area of epoxy coating formulated with $0.75 \mathrm{wt} . \% \mathrm{BIM}$ after $24 \mathrm{~h}$ polarization at $-1.2 \mathrm{~V} \mathrm{vs} . \mathrm{Ag} / \mathrm{AgCl}$ in $3.5 \mathrm{wt} . \% \mathrm{NaCl}$ solution is shown in Figure 9, where deposition of a layer can be clearly observed. Moreover, detection of $\mathrm{N}(4.16 \mathrm{wt} . \%)$ and C (13.34 wt.\%) in the EDS analysis can confirm the speculation made in the cathodic disbonding section relating to the engagement of the corrosion inhibitor in the film formation at the 
disbonding front. As mentioned before, the layer had an important role in the control of coating delamination through affecting the electrochemical reactions generation hydroxyl ions.



Figure 9. The result of SEM analysis of the ST37 sample surface beneath the disbonded area of epoxy coating formulated with $0.75 \mathrm{wt} \% \mathrm{BIM}$ after $24 \mathrm{~h}$ polarization at $-1.2 \mathrm{~V}$ vs. $\mathrm{Ag} / \mathrm{AgCl}$ in $3.5 \mathrm{wt} \%$ $\mathrm{NaCl}$ solution.

\section{Conclusions}

Assessment of the influence of benzoimidazole concentration on the cathodic delamination of epoxy coating applied on ST37 substrate came down to the following conclusions:

- The solution phase study indicated that addition of benzoimidazole to chloride solution decreased the corrosion of bare ST37 sample through development of a protective layer on the surface or stabilization of the corrosion products.

- Cathodic disbonding resistance of epoxy-polyamide coating was shown to be dependent on the inhibitor content.

- Inclusion of $0.75 \mathrm{wt} . \%$ corrosion inhibitor to the epoxy-polyamide coating formulation decreased the cathodic disbonded surface area effectively, which is consistent with the electrochemical data.

- The wet adhesion of the polymeric coating was significantly enhanced through the addition of 0.75 wt. $\%$ benzoimidazole.

Author Contributions: Conceptualization, R.N.; Analysis, S.N.; Interpretation of Data, S.N. and N.A.; Writing-Original Draft Preparation, S.N. and N.A.; Writing-Review \& Editing, R.N.; Supervision, R.N.

Funding: This research received no external funding.

Conflicts of Interest: The authors declare no conflict of interest.

\section{References}

1. Kamimura, T.; Kishikawa, H. Mechanism of cathodic disbonding of three-layer polyethylene-coated steel pipe. Corrosion 1998, 54, 979-987. [CrossRef]

2. Leidheiser, H.; Wang, W.; Lgetoft, L. The mechanism for cathodic delamination of organic coating from a metal surface. J. Prog. Org. Coat. 1983, 11, 19-40. [CrossRef]

3. Zhou, W.; Jeffers, T.E. Application temperature, cure, and film thickness affect cathodic disboniment of FBE coatings. Mater. Perform. 2006, 45, 24-28.

4. Grundmeier, G.; Stratmann, M. Adhesion and de-adhesion mechanisms at polymer/metal interfaces: Mechanistic understanding based on in situ studies of buried interfaces. Annu. Rev. Mater. 2005, 35, 571-615. [CrossRef] 
5. Nazarov, A.; Le Bozec, N.; Thierry, D. Assessment of steel corrosion and deadhesion of epoxy barrier paint by scanning Kelvin probe. Prog. Org. Coat. 2018, 114, 123-134. [CrossRef]

6. Parhizkar, N.; Shahrabi, T.; Ramezanzadeh, B. Steel surface pre-treated by an advance and eco-friendly cerium oxidenanofilm modified by graphene oxide nanosheets; electrochemical and adhesion measurements. J. Alloy. Compd. 2018, 747, 109-123. [CrossRef]

7. Sorensen, P.; Dam-Johansen, K.; Weinell, C.; Kiil, S. Cathodic delamination: Quantification of ionic transport rates along coating-steel interfaces. Prog. Org. Coat. 2010, 68, 70-78. [CrossRef]

8. Martinez, S.; Zulj, L.; Kapor, F. Disbonding of underwater-cured epoxy coating caused by cathodic protection current. Corros. Sci. 2009, 51, 2253-2258. [CrossRef]

9. Fu, A.; Cheng, Y. Characterization of corrosion of X65 pipeline steel under disbonded coating by scanning Kelvin probe. Corros. Sci. 2009, 51, 914-920. [CrossRef]

10. Mahdavian, M.; Attar, M. The effect of benzimidazole and zinc acetylacetonate mixture on cathodic disbonding of epoxy coated mild steel. Prog. Org. Coat. 2009, 66, 137-140. [CrossRef]

11. Leidheiser, H. Coatings. In Corrosion Mechanisms; Mansfeld, F., Ed.; Marcel Dekker: New York, NY, USA, 1986.

12. Schweitzer, P.A. Corrosion Engineering Handbook; CRC Press: Boca Raton, FL, USA, 2006.

13. Greenfield, D.; Scantlebury, D. The protective action of organic coatings on steel: A review. J. Cross. Sci. Eng. 2000, 3, 5 .

14. Forsgren, A. Corrosion Control through Organic Coatings; CRC Press: Boca Raton, FL, USA, 2006.

15. Naderi, R.; Attar, M. The role of zinc aluminum phosphate anticorrosive pigment in protective performance and cathodic disbondment of epoxy coating. Corros. Sci. 2010, 52, 1291-1296. [CrossRef]

16. Naderi, R.; Attar, M. Cathodic disbondment of epoxy coating with zinc aluminum polyphosphate as a modified zinc phosphate anticorrosion pigment. Prog. Org. Coat. 2010, 69, 392-395. [CrossRef]

17. Naderi, R.; Attar, M. Effect of zinc-free phosphate-based anticorrosion pigment on the cathodic disbondment of epoxy-polyamide coating. Prog. Org. Coat. 2014, 77, 830-835. [CrossRef]

18. Zhang, Z.; Chen, S.; Li, Y.; Li, S.; Wang, L. A study of the inhibition of iron corrosion by imidazole and its derivatives self-assembled films. Corros. Sci. 2009, 51, 291-300. [CrossRef]

19. Tan, A.; Soutar, A. Hybrid sol-gel coatings for corrosion protection of Copper. Thin Solid Film 2008, 516, 5706-5709. [CrossRef]

20. Yang, H. Plasma Treatment of Organic Inhibitors for Corrosion Protection of Aerospace Alloys. Master's Thesis, University of Cincinnati, Cincinnat, OH, USA, 2003.

21. Tadokoro, K.; Shoji, H.; Sakon, T.; Jitsuhara, I.; Yamasaki, M. Metallic Sheet Having rust-Preventive Organic Coating Thereon, Process for the Production Thereof and Treating Fluid Therefore. U.S. Patent 6,254,980, 3 July 2001.

22. Cook, R.L. Releasable Corrosion Inhibitor Compositions. U.S. Patent 6,933,046, 23 August 2005.

23. Brooman, E.W. Modifying organic coatings to provide corrosion resistance-Part III: Organic additives and conducting polymers. Met. Finish. 2002, 100, 104-110.

24. Izadi, M.; Shahrabi, T.; Ramezanzadeh, B. Active corrosion protection performance of an epoxy coating applied on the mild steel modified with an eco-friendly sol-gel film impregnated with green corrosion inhibitor loaded nanocontainers. Appl. Surf. Sci. 2018, 440, 491-505. [CrossRef]

25. Mahdavian, M.; Ashhary, S. Mercapto functional azole compounds as organic corrosion inhibitors in a polyester-melamine coating. Prog. Org. Coat. 2010, 68, 259-264. [CrossRef]

26. Ebrahimi-Mehr, M.; Shahrabi, T.; Hosseini, M. Determination of suitable corrosion inhibitor formulation for a potable water supply. Anti-Corros. Methods Mater. 2004, 51, 399-405. [CrossRef]

27. Beiro, M.; Collazo, A.; Izquierdo, M.; Novoa, X.; Perez, C. Characterization of barrier properties of organic paints: The zinc phosphate effectiveness. Prog. Org. Coat. 2003, 46, 97-106. [CrossRef]

28. Mousavifard, S.M.; MalekMohammadi Nouri, P.; Attar, M.M.; Ramezanzadeh, B. The effects of zinc aluminum phosphate (ZPA) and zinc aluminum polyphosphate (ZAPP) mixtures on corrosion inhibition performance of epoxy/polyamide coating. J. Ind. Eng. Chem. 2013, 19, 1031-1039.

29. Mahdavian, M.; Naderi, R.; Peighambari, M.; Hamidpour, M.; Haddadi, S. Evaluation of cathodic disbondment of epoxy coating containing azole compounds. J. Ind. Eng. Chem. 2014, 21, 1167-1173. [CrossRef] 
30. Hang, T.; Duong, N.; Truc, T.; Hoang, T.; Thanh, D.; Daopiset, S.; Boonplean, A. Effects of hydrotalcite intercalated with corrosion inhibitor on cathodic disbonding of epoxy coatings. J. Coat. Technol. Res. 2015, 12, 375-383. [CrossRef]

31. Ramezanzadeh, B.; Vakili, H.; Amini, R. The effects of addition of poly(vinyl) alcohol (PVA) as a greencorrosion inhibitor to the phosphate conversion coating on theanticorrosion and adhesion properties of the epoxy coating on thesteel substrate. Appl. Surf. Sci. 2015, 327, 174-181. [CrossRef]

32. Parhizkar, N.; Ramezanzadeh, B.; Shahrabi, T. Corrosion protection and adhesion properties of the epoxy coating applied on the steel substrate pre-treated by a sol-gel based silane coating filled with amino and isocyanate silane functionalized grapheme oxide nanosheets. Appl. Surf. Sci. 2018, 439, 45-59. [CrossRef]

33. Bentiss, F.; Jama, C.; Mernari, B.; El Attari, H.; El Kadi, L.; Lebrini, M.; Traisnel, M.; Lagrenee, M. Corrosion control of mild steel using 3,5-bis(4-methoxyphenyl)-4-amino-1,2,4-triazole in normal hydrochloric acid medium. Corros. Sci. 2009, 51, 1628-1635. [CrossRef]

34. Deflorian, F.; Rossi, S.; Fedel, M.; Motte, C. Electrochemical investigation of high-performance silane sol-gel films containing clay nanoparticles. Prog. Org. Coat. 2010, 69, 158-166. [CrossRef]

35. Nikpour, S.; Naderi, R.; Mahdavian, M. Fabrication of silane coating with improved protection performance using Mentha longifolia extract. J. Taiwan Inst. Chem. Eng. 2018, 88, 261-276. [CrossRef]

36. Bahrani, A.; Naderi, R.; Mahdavian, M. Chemical modification of talc with corrosion inhibitors to enhance the corrosion protective properties of epoxy-ester coating. Prog. Org. Coat. 2018, 120, 110-122. [CrossRef]

37. Dias, S.; Lamaka, S.; Nogueira, C.; Diamantino, T.; Ferreira, M. Sol-gel coatings modified with zeolite fillers for active corrosion protection of AA2024. Corros. Sci. 2012, 62, 153-162. [CrossRef]

38. Zheludkevich, M.; Poznyak, S.; Rodrigues, L.; Raps, D.; Hack, T.; Dick, L.; Nunes, T.; Ferreira, M. Active protection coatings with layered double hydroxide nanocontainers of corrosion inhibitor. Corros. Sci. 2010, 52, 602-611. [CrossRef]

39. Naderi, R.; Fedel, M.; Urios, T.; Poelman, M.; Olivier, M.; Deflorian, F. Optimization of silane sol-gel coatings for the protection of aluminium components of heat exchangers. Surf. Interface Anal. 2013, 45, 1457-1466. [CrossRef]

40. Ismail, I.; Harun, M. Cathodic disbonding of industrial chlorinated rubber-based primer used in rubber/metal composites: An electrochemical impedance spectroscopy analysis. Rubber Chem. Technol. 2016, 89, 712-723. [CrossRef]

41. Chen, Y.; Wang, X.; Li, Y.; Zheng, G.; Tu, X. Electrochemical impedance spectroscopy study for cathodic disbonding test technology on three layer polyethylene anticorrosive coating under full immersion and alternating dry-wet environments. Int. J. Electrochem. Sci. 2016, 11, 10884-10894. [CrossRef]

42. Hirayama, R.; Haruyama, S. Electrochemical impedance for degraded coated steel having pores. Corrosion 1991, 47, 952-957. [CrossRef]

43. Jorcin, J.; Aragon, E.; Merlatti, C.; Pebere, N. Delaminated areas beneath organic coating: A local electrochemical impedance approach. Corros. Sci. 2006, 48, 1779-1790. [CrossRef] 